\title{
Strong metal-support interaction in size-controlled monodisperse palladium-hematite nano- heterostructures during a liquid-solid heterogeneous catalysis
}

\author{
Biao Xu1 ${ }^{1}$, Hao Yang ${ }^{2}$, Gang Zhou ${ }^{3}$ and Xun Wang ${ }^{1 *}$
}

\begin{abstract}
Metal-semiconductor nanoheterostructure (NHS) exhibits fascinating catalytic performance due to the strong metal-support interaction (SMSI). SMSI in liquid-solid heterogeneous catalysis based on NHS was rarely investigated as compared to the gas-solid counterpart. Two issues, namely, the wet-chemical preparation of monodisperse model catalyst and in-situ characterization on the electronic structure, are challenging and studied here. The size of the metal catalyst was finely tuned in a $\mathrm{Pd}-\mathrm{Fe}_{2} \mathrm{O}_{3} \mathrm{NHS}$ and electrochemical test revealed that the electronic states differ significantly in liquid environment from in vacuum. The combined amendments resulted in a more reliable conclusion on the SMSI in Suzuki coupling. This study might give some clues on the illusive in-liquid structure-property relationships.
\end{abstract}

\section{INTRODUCTION}

In heterogeneous catalysis, nanoheterostructure (NHS) is an emerging material where the support and the metal unit are integrated as one nanosystem [1-3]. The electron/ atom transfer between the two segments would improve the performance, selectivity and stability of the metal catalyst, which is denoted as strong metal-support interaction (SMSI) [4-7]. While gas-solid heterogeneous catalysis sets the basis of chemical industry [8], the liquid-solid counterpart is also quite crucial, especially in fine chemicals [9]. However, most of the studies on SMSI were limited to gas-solid catalysis but very few were on liquid-solid ones. There are two challenges presented ahead.

The first issue is the preparation of monodisperse metal nanoparticles (NPs) on a support, which is crucial to the reliable acquisition on the size dependence in SMSI [10] and also will help to realize the goal, that is, the lowest consumption of noble metal for the highest efficiency in future practice. With the progress in the synthesis of mono- disperse metal nanocrystals (NCs) [11,12], it is convenient to prepare these metal NCs first and then sinter them with the oxide support, as demonstrated by Cargnello et al. [13]. However, the post-annealing might deteriorate the narrow size distribution and the metal-oxide interface is not natively formed. To gain a native metal-support interface, vapor phase methods, such as atomic layer deposition [14] and laser ablation [15], were recently developed to grow size-controllable metal NPs onto semiconductor nanowires (NWs). However, these vapor-phase methods were expensive and non-scalable. Furthermore the resultant catalyst is not dispersible in liquid phase for direct use. While non-uniform supported NPs would come from traditional deposition or impregnation methods [16], scalable wet-chemical methods to directly grow size-tunable monodisperse metal NCs on oxide support are still underdeveloped.

Besides the precise size control of the catalyst, the in-situ interrogation on the electronic structure of the catalyst is also vital to obtain a real view on the structure-activity relationship [17]. In operando conditions, the adsorption of reactant molecules, either gaseous [18] or liquid ones [19] to the solid phase, would alter the electronic structure of the catalysts to a certain extent. Hence, the traditional and routinely used vacuum characterizations might be misleading. Gas-phase in-situ techniques have been developed in recent years to examine the gas-solid reactions [20], while their liquid-phase counterparts remain retarded [21]. Appropriate methods to characterize the electronic structure of the supported catalyst in liquid still remain scarce. Conventional eletronic spectra, such as X-ray photoelectron spectra (XPS) and ultraviolet photoelectron spectroscopy (UPS) are not compatible in liquid phase, while only the expensive scanning tunneling microscopy (STM) [17] or $\mathrm{X}$-ray absorption spectra (XAS) [21] met this demand.

\footnotetext{
${ }^{1}$ Department of Chemistry, Tsinghua University, Beijing 100084, China

${ }^{2}$ Department of Materials Science and Engineering, Tsinghua University, Beijing 100084, China

${ }^{3}$ State Key Laboratory of Chemical Resource Engineering, Beijing University of Chemical Technology, Beijing 100029, China

Corresponding author (email: wangxun@mail.tsinghua.edu.cn)
} 
The combination of size regulated model catalyst and in-situ characterization is highly desirable for the study of SMSI, but rarely achieved in a liquid-solid case. To solve the above-mentioned issues, we report here the direct, size-controllable and wet-chemical synthesis of monodisperse Pd NPs supported on hematite nanorods (NRs) and the investigation on the SMSI via liquid-phase characterizations. The famous Suzuki-Miyaura reaction catalyzed by $\mathrm{Pd}$ was chosen as the model reaction. Hematite, as a useful and earth-abundant semiconducting oxide, was chosen as the support material. We found that after adsorption of either the solvent or the reactant, the electrochemical and chemical properties, associated with electronic structures of NHSs, pronouncedly changed, not always the same as those in vacuum. Intuitively, the view from the in-situ study brings us closer to the truth and this study will inspire the more reliable understanding on the size- and reaction environment-dependence in the liquid-phase SMSI.

\section{EXPERIMENTAL METHODS}

\section{Synthesis}

\section{Chemicals}

All the reagents were purchased from SCRC or Alfa. Deionized water was used.

\section{Synthesis of hematite $\left(\mathrm{Fe}_{2} \mathrm{O}_{3}\right) \mathrm{NRs}$}

$0.60 \mathrm{~mL}$ of $\mathrm{FeCl}_{3}(1.0 \mathrm{M})$ and $1.08 \mathrm{~mL}$ of $\mathrm{NH}_{4} \mathrm{H}_{2} \mathrm{PO}_{4}(0.02$ $\mathrm{M})$ was added to $28 \mathrm{~mL}$ water, sealed in a $50-\mathrm{mL}$ teflonlined autoclave and heated at $220^{\circ} \mathrm{C}$ for $2 \mathrm{~h}$. After the reaction, the product was washed with water and ethanol, centrifuged and re-dispersed in $6.0 \mathrm{~mL}$ of water for further use. For electrochemical test, to the $\mathrm{Fe}_{2} \mathrm{O}_{3}$ product in $6 \mathrm{~mL}$ of water was added $24 \mathrm{~mL}$ formamide, $0.24 \mathrm{~g}$ polyvinylpyrrolindone (PVP) $\left(M_{\mathrm{w}}=8,000\right)$ and heated at $85^{\circ} \mathrm{C}$ for $1.5 \mathrm{~h}$. The PVP-treated $\mathrm{Fe}_{2} \mathrm{O}_{3}$ NRs were confirmed by XPS that their surface was capped with PVP (see Supplementary Information, part 4-1).

\section{Synthesis of $7 \mathrm{~nm} \mathrm{Pd}-\mathrm{Fe}_{2} \mathrm{O}_{3} \mathrm{NHSs}$ (Sample 1)}

To the as prepared $\mathrm{Fe}_{2} \mathrm{O}_{3} \mathrm{NRs}(0.6 \mathrm{mmol} \mathrm{Fe}$, in $6.0 \mathrm{~mL}$ water) was added $24 \mathrm{~mL}$ formamide, $0.24 \mathrm{~g}$ PVP $\left(M_{\mathrm{w}}=8,000\right)$ and $0.036 \mathrm{mmol} \mathrm{K}_{2} \mathrm{PdCl}_{4}(0.36 \mathrm{~mL} \times 0.10 \mathrm{M})$ and heated at $85^{\circ} \mathrm{C}$ for $1.5 \mathrm{~h}$. After that, the product was washed and redispersed in $6 \mathrm{~mL}$ ethanol. $1 \mathrm{~mol} \%$ (Sample 1-2) and 3 mol\% (Sample 1-3) Pd-to-Fe loading could be obtained via changing the amount of $\mathrm{K}_{2} \mathrm{PdCl}_{4}$ to $0.006 \mathrm{mmol}$ and 0.018 mmol, respectively.

\section{Synthesis of $10 \mathrm{~nm} \mathrm{Pd}-\mathrm{Fe}_{2} \mathrm{O}_{3} \mathrm{NHSs}$ (Sample 2)}

To the as prepared $\mathrm{Fe}_{2} \mathrm{O}_{3} \mathrm{NRs}(0.6 \mathrm{mmol} \mathrm{Fe}$, in $4.0 \mathrm{~mL}$ water) was added $16 \mathrm{~mL}$ formamide, $0.24 \mathrm{~g} \operatorname{PVP}\left(M_{\mathrm{w}}=8,000\right)$ and $0.036 \mathrm{mmol} \mathrm{K}_{2} \mathrm{PdCl}_{4}(0.36 \mathrm{~mL} \times 0.10 \mathrm{M})$ and heated at $85^{\circ} \mathrm{C}$ for $1.5 \mathrm{~h}$. The product was washed and redispersed in $6 \mathrm{~mL}$ ethanol.

Synthesis of Br-capped $7 \mathrm{~nm} \mathrm{Pd-Fe} \mathrm{O}_{3} \mathrm{NHSs}$ (Sample 3)

It was similar with Sample 2 except for addition of $44 \mathrm{mg}$ $\mathrm{KBr}$.

\section{Synthesis of $4 \mathrm{~nm} \mathrm{Pd}-\mathrm{Fe}_{2} \mathrm{O}_{3} \mathrm{NHSs}$ (Sample 4)}

It was similar with Sample 1 except for addition of $200 \mathrm{mg}$ $\mathrm{KBr}$.

Synthesis of $1.8 \mathrm{~nm} \mathrm{Pd-Fe}{ }_{2} \mathrm{O}_{3} \mathrm{NHSs}$ (Sample 5)

It was similar with Sample 1 except for addition of $440 \mathrm{mg}$ $\mathrm{KBr}$.

\section{Synthesis of $7 \mathrm{~nm}$ Pd NPs (Sample 6)}

$25 \mathrm{mg}$ PVP $\left(M_{\mathrm{w}}=88,000\right)$ was dissolved in $3.3 \mathrm{~mL}$ formamide and heated to $150^{\circ} \mathrm{C}$. $5.0 \mathrm{mg} \mathrm{PdCl}_{2}$ was dissolved in $1.6 \mathrm{~mL}$ formamide and injected to the above solution and it was kept at $150^{\circ} \mathrm{C}$ for $30 \mathrm{~min}$. Acetone was added and the product was centrifuged and redispersed in ethanol.

\section{Synthesis of $10 \mathrm{~nm}$ Pd NPs (Sample 7)}

$25 \mathrm{mg} \operatorname{PVP}\left(M_{\mathrm{w}}=88,000\right)$ was dissolved in $4 \mathrm{~mL}$ formamide and heated to $150^{\circ} \mathrm{C}$. To this solution $0.30 \mathrm{~mL} \mathrm{~K}$ Pd$\mathrm{Cl}_{4}(0.10 \mathrm{M}$ in water $)$ was injected and it was kept at $150^{\circ} \mathrm{C}$ for $10 \mathrm{~min}$. The final products could be obtained by adding acetone and centrifuge.

\section{Synthesis of non-uniform $4 \mathrm{~nm} \mathrm{Pd-Fe} \mathrm{O}_{3} \mathrm{NPs}$ (Sample 8)}

To the as prepared $\mathrm{Fe}_{2} \mathrm{O}_{3}$ NRs $(0.6 \mathrm{mmol} \mathrm{Fe}$, in $2 \mathrm{~mL}$ water) was added $8 \mathrm{~mL}$ formamide, $0.24 \mathrm{~g} \mathrm{PVP}\left(M_{w}=80,000\right)$ and $0.036 \mathrm{mmol} \mathrm{K}_{2} \mathrm{PdCl}_{4}(0.36 \mathrm{~mL} \times 0.10 \mathrm{M})$ and heated at $85^{\circ} \mathrm{C}$ for $1.5 \mathrm{~h}$.

\section{Catalysis}

After optimizations, we chose the following condition for catalysis tests: temperature: $300 \mathrm{~K}$, time: $0-18 \mathrm{~h}$, the amount of phenyl bromide: $0.50 \mathrm{mmol}$, the amount of phenylboronic acid: $0.65 \mathrm{mmol}$, the amount of $\mathrm{K}_{2} \mathrm{CO}_{3}: 1.00$ mmol, solvent: $1.5 \mathrm{~mL}$ water and $1.5 \mathrm{~mL}$ ethanol, and the amount of catalyst: $0.5 \mathrm{~mol} \%$.

We found that $300 \mathrm{~K}$ is enough to activate the coupling reaction. The optimized molar ratio of phenylboronic acid to phenyl bromide is around 1 to 1.5 . When this ratio is larger than 2, self-coupling of phenylboronic acid leading to by-product is accelerated. The amount of $\mathrm{K}_{2} \mathrm{CO}_{3}$ is around 2 to 4 equivalent amounts to phenyl bromide. The solvent was chosen as a $1: 1(\mathrm{v} / \mathrm{v})$ water-ethanol mixture, because both the organic compound and the base $\left(\mathrm{K}_{2} \mathrm{CO}_{3}\right)$ would be dissolved and activated. We have also tested the 
amount of catalyst and found that $0.5 \mathrm{~mol} \%$ is the best considering the reaction rate and the dosage.

\section{Characterizations}

Electron microscopy and elemental mapping were performed on a Tecnai G2 F20 S-Twin high-resolution transmission electron microscope (HRTEM) at $200 \mathrm{kV}$. C -corrected HRTEM were carried out on a Tecnai Titan 80-300 TEM.

Powder X-ray diffraction (PXRD) profiles were collected on a Bruker D8 Advance X-ray diffractometer using Cu Ka radiation $(\lambda=1.5418 \AA$ ). XPS were recorded on a PHI Quantera SXM spectrometer using monochromatic Al Ka $\mathrm{X}$-ray sources $(1,486.6 \mathrm{eV})$ at $2.0 \mathrm{kV}$ and $20 \mathrm{~mA}$, and all the peak values were calibrated according to $C_{1 s}$ peak $(284.6$ $\mathrm{eV})$. Inductively coupled plasma atomic emission spectroscopy (ICP-OES) technique was taken on a 2RIS Intrepid II XSP ICP-OES. ATR-IR was carried out on a Perkin Elmer Spectrum GX FTIR system.

Mott-Schottky Plot was measured on a CHI 650D electrochemical work station using an impedance-capacitance technique. Saturated calomel electrode (SCE) and platinum flag were used as reference and counter electrode, respectively. The working electrode was made by drop-casting $50 \mu \mathrm{L}$ of the hematite or Pd-hematite dispersion $(0.60$ mmol Fe in $6.0 \mathrm{~mL}$ ) onto a $2 \mathrm{~cm} \times 2 \mathrm{~cm}$ fluorine-doped Tin oxide coated glass slide and then calcined at $450^{\circ} \mathrm{C}$ in $\mathrm{Ar}$ for $1 \mathrm{~h}$. The measurement was performed in a $30 \mathrm{~mL}$ water/ ethanol $(\mathrm{v} / \mathrm{v}=1: 1)$ solution containing $0.01 \mathrm{~mol} \mathrm{~K}_{2} \mathrm{CO}_{3}(\mathrm{pH}$ 12). The parameters were as following: voltage scan: -1.0 to $0 \mathrm{~V}$ vs. SCE, disturbing amplitude: $0.01 \mathrm{~V}$, frequency: $1 \mathrm{kHz}$. Before the test, the working electrode was immersed in the solution to achieve equilibrium for $6 \mathrm{~h}$. During the test, Ar was bubbled into the solution and the temperature was maintained at $300 \mathrm{~K}$ in a water bath.

\section{RESULTS AND DISCUSSION}

Formamide was chosen as both the solvent and reducing agent for its efficiency in synthesizing monodisperse metal NPs [22]. We extended this system to the synthesis of $\mathrm{Pd}-\mathrm{Fe}_{2} \mathrm{O}_{3}$ NHSs from hydrothermally prepared $\alpha-\mathrm{Fe}_{2} \mathrm{O}_{3}$ NRs [23]. The NRs were dispersed in formamide with palladium precursor $\left(\mathrm{K}_{2} \mathrm{PdCl}_{4}\right)$, surfactant $\mathrm{PVP}$, salts $(\mathrm{KCl}$ or $\mathrm{KBr})$ and heated to initiate the reduction of $\mathrm{Pd}(\mathrm{II})$. (7.0 \pm 1.0)-nm-Pd NPs on $\alpha-\mathrm{Fe}_{2} \mathrm{O}_{3}$ NRs with a loading amount (confirmed by ICP-OES) of $6 \mathrm{~mol} \%$ Pd-to-Fe (Sample 1) could be obtained (Fig. 1a). The size of Pd NPs could also be tuned to $10.0 \pm 1.4 \mathrm{~nm}$ (Sample 2, Fig. S1a). The temperature and the concentration of $\mathrm{Pd}$ should be carefully regulated to controllably initiate the heterogeneous nucleation and inhibit the homogeneous nucleation of the Pd NCs. Different crystal planes were observed in HRTEM
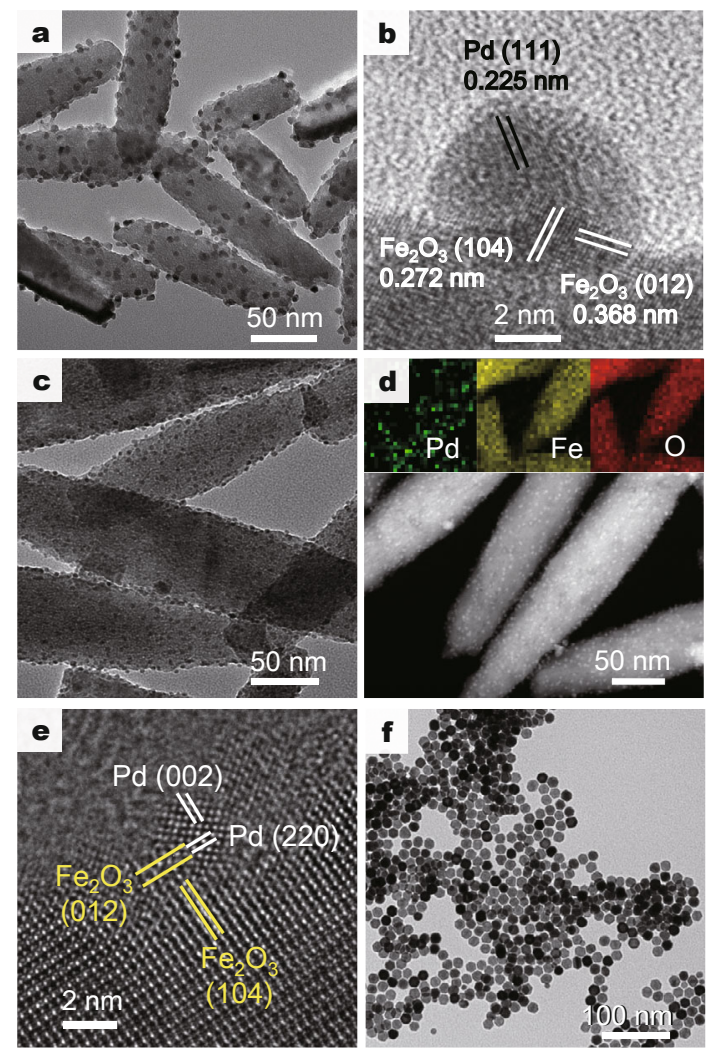

Figure 1 TEM images of (a) Sample 1, (b) HRTEM of Sample 1, (c) Sample 4, (d) HAADF-STEM and elemental mapping of Sample 4, (e) Cs-corrected HRTEM of Sample 5, (f) TEM image of Sample 7.

and assigned to $\mathrm{Pd}$ (JCPDS 46-1043) and $\alpha-\mathrm{Fe}_{2} \mathrm{O}_{3}$ (JCPDS 33-0664) (Figs 1b and e). (012) plane of hematite was present at the interface parallel to (220) plane of Pd (Fig. 1e). It is known that bromide ion is efficient in tuning the metal nanostructures, influencing their nucleation and growth [24]. So we could also obtain heterostructures with $7.0 \pm$ $0.7 \mathrm{~nm}$ Pd (Sample 3, Fig. S1b, Pd/Fe = 6 mol\%), $4.0 \pm 0.3$ $\mathrm{nm}$ Pd (Sample 4, Figs $1 \mathrm{c}$ and $\mathrm{S} 1 \mathrm{c}, \mathrm{Pd} / \mathrm{Fe}=6 \mathrm{~mol} \%$ ) and 1.8 $\pm 0.2 \mathrm{~nm}$ Pd clusters (Sample 5, Figs 1e and S1e, $\mathrm{Pd} / \mathrm{Fe}=6$ mol\%) through adding different amount of KBr. HAADFSTEM image confirmed the heterostructure via Z-contrast (Fig. 1d). EDX elemental mapping (Fig. 1d) indicated that $\mathrm{Fe}$ and $\mathrm{O}$ were uniformly distributed and $\mathrm{Pd}$ was scattered as small dots. The phase of $\alpha-\mathrm{Fe}_{2} \mathrm{O}_{3}$ was verified by PXRD and $\mathrm{Pd}$ phase appeared as weak and broadened peaks at $40.0^{\circ}(111)$ and $46.6^{\circ}$ (200) (Fig. S2) due to its fine grain size.

Based on the finely-tuned NHSs, we assayed the catalytic performance in a Suzuki-Miyaura reaction [25]. The Suzuki-Miyaura reaction involves the coupling of a halobenzene and aromatic boronic acid, catalyzed by homogeneous [26] or heterogeneous [27] Pd (0) species. Usually, iodobenzene is the most active substrate, bromobenzene is 
weaker and chlorobenzene is the most inert [26]. A few reports have dealt with room temperature (RT) reaction between bromobenzene and benzene-boronicacid [28]. For the convenience of further in-solution characterization, we chose phenyl bromide and RT to perform our catalysis. In $18 \mathrm{~h}$, at $300 \mathrm{~K}$, elegant conversion and yield from 70\% to $>99 \%$ were obtained for different substrates at a catalyst-to-substrate molar ratio $(\mathrm{C} / \mathrm{S})$ of $0.5 \mathrm{~mol} \%$ (Table $\mathrm{S} 1$ ). All the products were purified by column chromatography and verified by ${ }^{1} \mathrm{H}$ NMR (see Supplementary Information, part 3-3).

The relatively inert 4-methoxyl bromobenzene and bezene boronic acid were chosen to calibrate the activity of different NHSs (Table S2). The Turnover Frequency (TOF) was calculated (based on the total mole of Pd) and is listed in Table S2 and plotted as Fig. 2. Among chloride-directing synthesized NHSs, the 7-nm one (Sample 1) was more efficient than the 10-nm one (Sample 2). For bromide-assisted synthesized NHSs, $7 \mathrm{~nm}$-one (Sample 3) is worse than the same-size Cl-capped NHSs (Sample 1), while $4 \mathrm{~nm}$ one (Sample 4) showed comparable TOF as Sample 1, chloride-directed one. The 1.8-nm clusters-on-hematite (Sample 5) exhibited the best performance, and the TOF value is the best among those of the reported heterogeneous Pd catalyst, under RT. We also prepared the identical-sized Pd NPs in the same system. In the same system, $7.0 \pm 0.9 \mathrm{~nm}$ (Sample 6, Fig. S1f) and $10.0 \pm 0.7 \mathrm{~nm}$ (Sample 7, Fig. 1f) Pd NPs could be synthesized, exhibiting the yield of $33 \%$ and $20 \%$, respectively. Their TOF values were significantly lower than those of the same-sized $\mathrm{Pd}-\mathrm{Fe}_{2} \mathrm{O}_{3}$ NHSs, as an

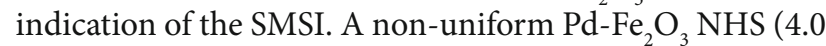
$\pm 2.0 \mathrm{~nm}$, Sample 8, Fig. S1g) was also tested, for comparison with the uniform counterpart, emphasizing the importance of monodisperse model catalyst. Then the reaction was proven to be heterogeneous by filtration experiment, which is also consistent with the literature on the catalysis of Suzuki coupling by PVP-capped Pd NPs [29]. Finally

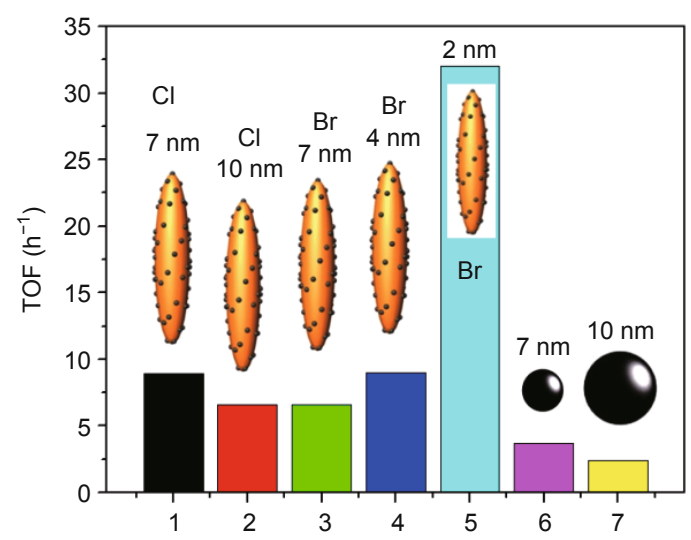

Figure 2 TOF values of different samples in Suzuki coupling. we measured the kinetic curves of different samples and fit them to obtain the initial reaction rate according to a Langmuir surface single molecule mechanism (part 3-2, in the Supplementary Information).

According to the above results, we adopted an atomistic model (Fig. S5) to explain the reactivity of the different-sized NHSs (see Supplementary Information, part 5) [13]. For bare Pd NPs, only surface atoms were dominated, while if the support $\left(\mathrm{Fe}_{2} \mathrm{O}_{3}\right.$ here $)$ was connected, considerable perimeter and corner atoms should be considered. The reactivities of different-sized Pd NPs and NHSs corresponded well with this model (see Supplementary Information, part 5) quantitatively, indicating that the perimeter and corner sites were more active than the surface sites due to lower coordinated numbers and positive responses from the SMSI (e.g., charge transfer).

It is well known that in heterogeneous catalysis, the electronic structure governs the catalytic performance. XPS is a routinely used technique to investigate the charge transfer in supported catalysts. $\mathrm{Pd} \mathrm{NPs}$ and $\mathrm{Pd}-\mathrm{Fe}_{2} \mathrm{O}_{3}$ NHSs were subjected for XPS (Figs $3 \mathrm{a}$ and $\mathrm{b}$ ) in vacuum. In general, the band bending model was proposed in metal-semiconductor junctions to give a phenomenological description or explanation for the charge transfer of NHSs [30]. In this case, electron was transferred to hematite because the Fermi energy $\left(E_{\mathrm{f}}\right)$ of hematite was lower than that of Pd (Scheme 1a, see Supplementary Information, part 4-1) [30]. Similar XPS spectra were observed for $10 \mathrm{~nm}$ Pd NPs and $10 \mathrm{~nm} \mathrm{Pd}-\mathrm{Fe}_{2} \mathrm{O}_{3}$ NHSs (Fig. S4-1). In terms of SMSI, other possibility than electron transfer, such as encapsulation, alloying and inter-diffusion could be excluded [6] (See Supplementary Information, part 4-1).

To elucidate the nature and effect of the SMSI of Pd$\mathrm{Fe}_{2} \mathrm{O}_{3}$ NHSs in vacuum, we performed theoretical investigations using density functional theory (DFT). First of all, we found that the Pd atoms of the $\mathrm{Pd}_{8}$ cluster-like NP as much as possible bind to the 3 -fold coordinated oxygen atoms $\left(\mathrm{O}_{3 \mathrm{c}}\right)$ of (012) surface of $\mathrm{Fe}_{2} \mathrm{O}_{3}$ (Fig. S6a), resembling

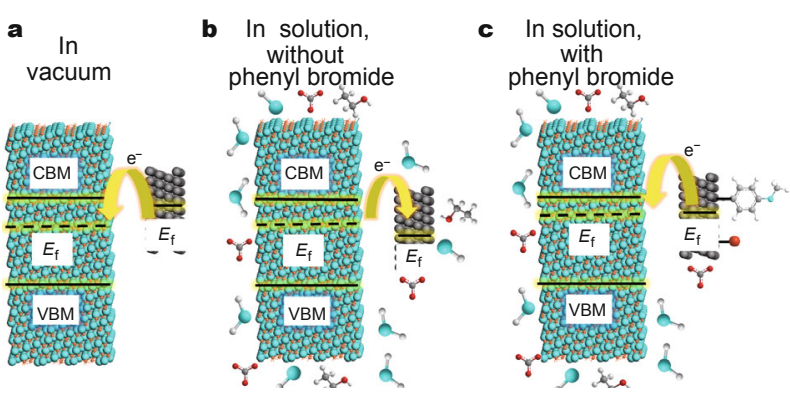

Scheme 1 Band alignment of $\mathrm{Pd}-\mathrm{Fe}_{2} \mathrm{O}_{3}$ NHSs in different environments. Atom denotation: oxygen-blue, carbon-light grey, hydrogen-white, bromine-red, palladium-black, iron-orange. CBM: conduction-band minimum; VBM: valence-band maximum. 
a
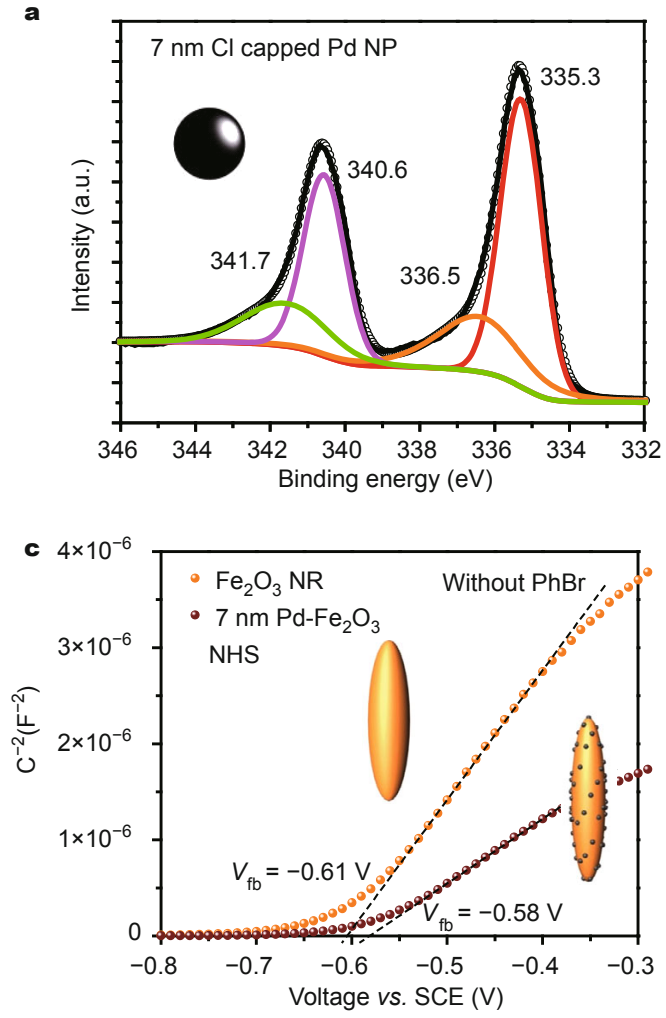

b
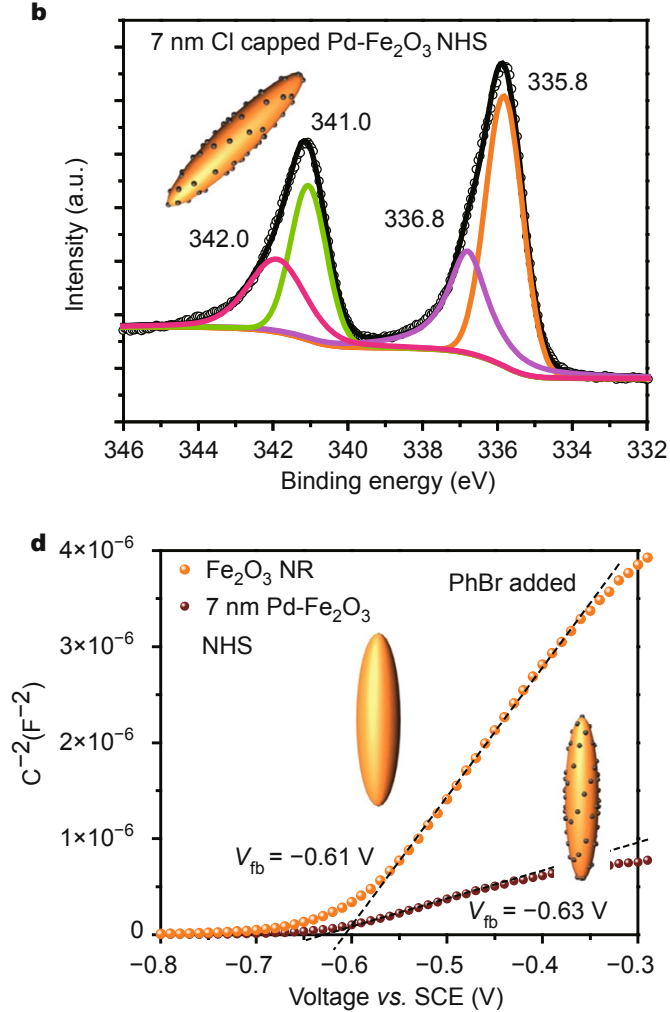

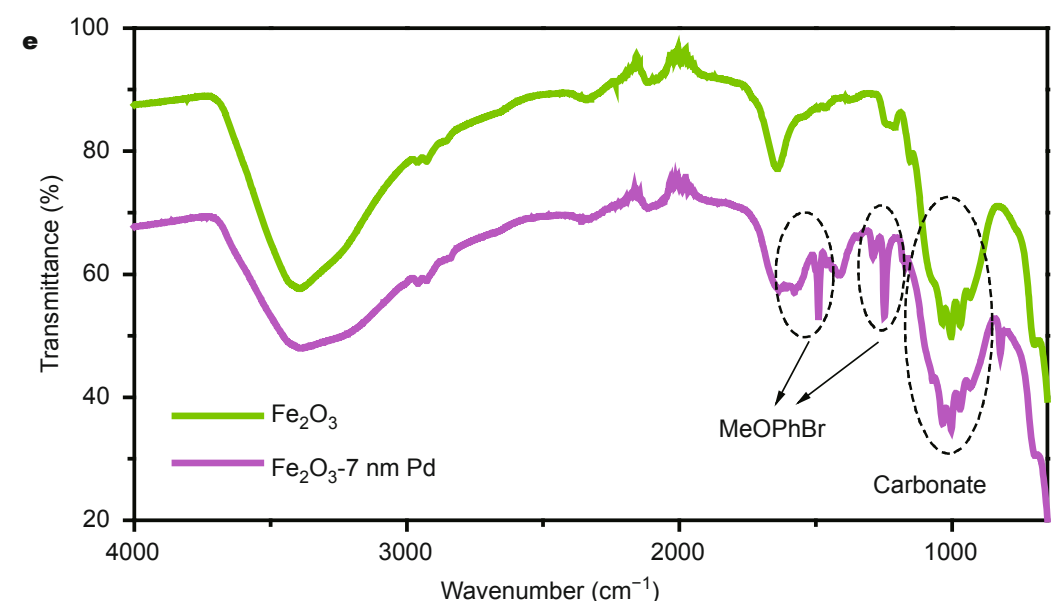

Figure 3 Pd 3d XPS spectra of (a) Pd NPs, (b) Pd-Fe $\mathrm{O}_{3}$ NHSs, Mott-Schottky Plot (c) without, (d) with addition of phenyl bromide, (e) ATR-IR spectra.

the case of Pt-ceria system [31]. However, only part of $\mathrm{O}_{3 c}$ atoms were saturated ultimately, due to the lattice mismatch between the two segments of the NHSs (Fig. S6b). Even so, the bonding model can also result in a well-defined Pd$\mathrm{Fe}_{2} \mathrm{O}_{3}$ interface, as shown in Fig. S6. Bader charge analysis indicated that every bound $\mathrm{Pd}$ atom donated $0.21-0.4$ electrons to $\mathrm{Fe}_{2} \mathrm{O}_{3}$ support through the $\mathrm{Pd}-\mathrm{O}$ bonds, while other Pd atoms even at the interface had no contribution to the process, as shown in the electron density difference plot
(Fig. 4a). This result was not only consistent with our XPS measurements in vacuum, but also implied a unique SMSI in such type of partially bonded NHSs (electron transfer only occurring through $\mathrm{Pd}-\mathrm{O}$ bonds). In contrast to the $\mathrm{Pd}_{8}$ $\mathrm{NP}$, the accepted electrons were delocalized at undercoordinated 5-fold $\mathrm{Fe}$ atoms $\left(\mathrm{Fe}_{5 \mathrm{c}}\right.$ ) of the (012) surface of $\mathrm{Fe}_{2} \mathrm{O}_{3}$ support and some sub-surface ones, thereby resulting in most of $\mathrm{Fe}_{5 \mathrm{c}}$ atoms, whether bonded or not, to be reduced to $\mathrm{Fe}^{2+}$ (Fig. 4b). This would facilitate the catalytic reactions 

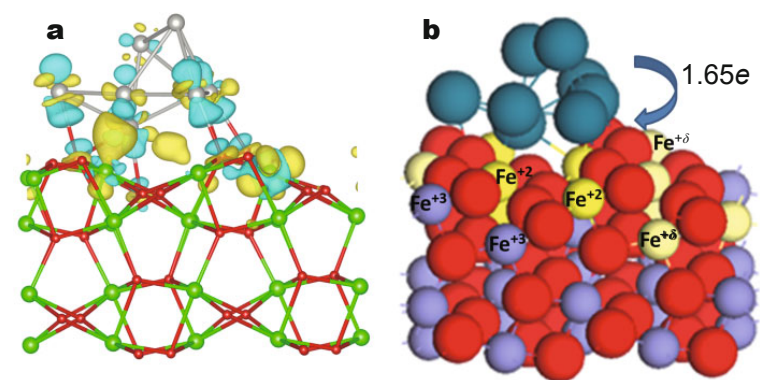

Figure 4 (a) Isosurface plot of the electron density difference between $\mathrm{Pd}_{8}-\mathrm{Fe}_{2} \mathrm{O}_{3}$ NHS and $\mathrm{Fe}_{2} \mathrm{O}_{3}(012)$ surface plus $\mathrm{Pd}_{8}$ cluster-like NP at the isovalue of $0.015 \mathrm{e} / \AA^{3}$. The silver, red and green balls correspond to the $\mathrm{Pd}, \mathrm{O}$ and $\mathrm{Fe}$ atoms, respectively. The yellow areas indicate electron gain, whereas the blue areas indicate electron loss. (b) Charge transfer from $\mathrm{Pd}_{8}$ to $\mathrm{Fe}_{2} \mathrm{O}_{3}$ and distribution of reduced $\mathrm{Fe}^{+2} / \mathrm{Fe}^{+\delta}$ in $\mathrm{Fe}_{2} \mathrm{O}_{3}$. The yellow, pale yellow and blue balls correspond to $\mathrm{Fe}^{+2}, \mathrm{Fe}^{+\delta}(\delta=2-3), \mathrm{Fe}^{+3}$, respectively.

that the $\mathrm{Fe}_{2} \mathrm{O}_{3}$ support involves, such as low temperature CO oxidation [32].

After primary investigation on the electronic structures by in-vacuum XPS route, we turned to a liquid one. MottSchottky plot, as a capacitance-voltage scan, was widely used to characterize the flat band potential of a semiconductor [33]. Flat band condition is met at the intercept of Mott-Schottky plot at the $\mathrm{x}$ axis (voltage) and this intercept stands for the $E_{\mathrm{f}}$ level of the semiconductor. The equation for Mott-Schottky plot is depicted in Supplementary Information, part 4-3. The positive slope of the Mott-Schottky plot for $\mathrm{Fe}_{2} \mathrm{O}_{3}$ NRs indicates its n-type nature [28] (Fig. 3c). The flat band potential $\left(V_{\mathrm{fb}}\right)$ value in ethanol/water/ $\mathrm{K}_{2} \mathrm{CO}_{3}$ solution of the $\mathrm{Fe}_{2} \mathrm{O}_{3}$ NRs and $\mathrm{Pd}-\mathrm{Fe}_{2} \mathrm{O}_{3}$ NHSs were measured to be $-0.61 \mathrm{~V}$ and $-0.58 \mathrm{~V}$ vs. SCE $(\mathrm{pH} 12,+0.11 \mathrm{~V}$ and $+0.14 \mathrm{~V} v s$. reversible hydrogen electrode (RHE), or $+4.61 \mathrm{~V}$ and $+4.64 \mathrm{~V} v s$. vacuum), respectively (the deviations were less than $\pm 0.01 \mathrm{~V}$, see Fig. S4-3). An observable decrease of $0.03 \mathrm{eV}$ for the $E_{\mathrm{f}}$ is found after Pd loading, indicating that the $E_{\mathrm{f}}$ was pulled down by Pd and the electrons transferred from $\mathrm{Fe}_{2} \mathrm{O}_{3}$ to $\mathrm{Pd}$ (Scheme 1b) [30]. This result was also similar with $n-\mathrm{TiO}_{2}-\mathrm{Pd}$ Schottky junction [34]. In previous literature, the adsorption of water [35,36], ethanol [37,38], $\mathrm{OH}^{-}[19]$ and $\mathrm{CO}_{3}^{2-}[39]$ on hematite or $\mathrm{Pd}$ had been studied. Here, $E_{\mathrm{f}}$ of $\mathrm{Fe}_{2} \mathrm{O}_{3}$ upshifted from -4.85 $\mathrm{eV}$ in vacuum [40] to around $-4.61 \mathrm{eV}\left(V_{\mathrm{fb}}=+4.61 \mathrm{~V} v s\right.$. vacuum) in solution, due to the adsorption of liquid species. In metal-semiconductor heterostructures, because the electron density of the metal largely surpasses the semiconductor, the $E_{\mathrm{f}}$ is pinned at the metal level [30]. In our case, the $\mathrm{Pd}-\mathrm{Fe}_{2} \mathrm{O}_{3}$ holds an $E_{\mathrm{f}}$ at about $-4.64 \mathrm{eV}$ and this approximately stands for $E_{\mathrm{f}}$ of $\mathrm{Pd}$. The $E_{\mathrm{f}}$ of Pd might not change much in liquid as compared to vacuum, so it became lower than that of hematite and charge transfer from $\mathrm{Fe}_{2} \mathrm{O}_{3}$ to $\mathrm{Pd}$ occurred.
Moreover, we also studied the effect of selected reactants on the properties of NHSs. After adding bromoanisole, the $V_{\mathrm{fb}}$ value of the bare $\mathrm{Fe}_{2} \mathrm{O}_{3}$ NRs $(-0.61 \mathrm{~V})$ remained the same while the Pd-Fe $\mathrm{O}_{3}$ NHSs shifted to $-0.63 \mathrm{~V}$ by $-0.05 \mathrm{~V}$ (Fig. 3d). In heterogeneous Suzuki coupling reaction [41-43], the initial step involves oxidative addition of $\mathrm{MeOPhBr}$ to $\mathrm{Pd}(0)$, forming a MeOPh-Pd-Br complex that is bond to the surface of Pd (0) NCs [42]. The significant change in $V_{\mathrm{fb}}$ of the $\mathrm{Pd}-\mathrm{Fe}_{2} \mathrm{O}_{3}$ NHSs might stem from the strong adsorption of 4-bromoanisole onto $\mathrm{Pd}$ and the upshift of the $E_{\mathrm{f}}$ of $\mathrm{Pd}$ (nearly the same as $E_{\mathrm{f}}$ of $\mathrm{Pd}-\mathrm{Fe}_{2} \mathrm{O}_{3}$ ) to about $-4.58 \mathrm{eV}(-0.63 \mathrm{~V} v s$. SCE here). In this case the electrons would flow from $\mathrm{Pd}$ to $\mathrm{Fe}_{2} \mathrm{O}_{3}$ again (Scheme 1c). Then the total $E_{\mathrm{f}}$ of the $\mathrm{Pd}-\mathrm{Fe}_{2} \mathrm{O}_{3} \mathrm{NHS}$ ascended. Similar results were found for $10 \mathrm{~nm} \mathrm{Pd}-\mathrm{Fe}_{2} \mathrm{O}_{3}$ NHSs (Supplementary Information, part 4-3). In contrast, in bromide capped $\mathrm{Pd}-\mathrm{Fe}_{2} \mathrm{O}_{3} \mathrm{NHS}$, the flatband potentials were complex and different due to the smaller size of Pd NCs, as shown in Table S5, part 4-3. The adsorption of MeOPhBr on Pd$\mathrm{Fe}_{2} \mathrm{O}_{3}$ was further confirmed by surface-sensitive ATR-IR (Fig. 3e). The $\mathrm{Fe}_{2} \mathrm{O}_{3}$ NRs and the $\mathrm{Pd}-\mathrm{Fe}_{2} \mathrm{O}_{3}$ NHS samples were all equilibrated with a bromoanisole- $\mathrm{K}_{2} \mathrm{CO}_{3}$ solution in ethanol/water before ATR-IR tests. In Fig. 3e, the peaks around $1000 \mathrm{~cm}^{-1}$ are presented for both samples and assigned as carbonate species. The peaks located in the range from 1600 to $1000 \mathrm{~cm}^{-1}$ and the fingerprint peak at $\sim 800$ $\mathrm{cm}^{-1}$ were found for Pd-Fe $\mathrm{O}_{3}$ NHSs but absent for $\mathrm{Fe}_{2} \mathrm{O}_{3}$ NRs (The detailed assignments for the peaks are listed in Supplementary Information, part 4-4). This provided firm evidence that the bromoanisole adsorbed on the Pd surfaces but not onto the $\mathrm{Fe}_{2} \mathrm{O}_{3}$.

In the previous studies on liquid-phase SMSI, the authors usually characterize the electronic structure of the NHS catalyst in vacuum, using XPS [44] or XAS [45]. They conclude that electrons flow to or are extracted from the metal NPs to the support, through these in-vacuum observations. In our case, we would conclude that electron extraction from $\mathrm{Pd}$ to $\mathrm{Fe}_{2} \mathrm{O}_{3}$ would lead to better performance of the Pd catalyst, from the vacuum XPS (scheme 1a). However, totally different views would be obtained through in-situ examinations (scheme $1 \mathrm{~b}$ and c). It is clearly demonstrated here that the in-liquid characterization would be closer to the truth and the in-vacuum observation might lead to an illusion.

The favored activation of bromoanisole on $\mathrm{Pd}$ in the NHSs might originate from the electron communication across the $\mathrm{Pd}-\mathrm{Fe}_{2} \mathrm{O}_{3}$ interface. The electronic charge of metallic NCs exerts a major effect on their catalytic reactivity [46]. The electron transfer usually accompanies the partially charged species, such as $\mathrm{Pd}^{\delta+}, \mathrm{Pd}^{\delta-}$ or $\mathrm{Fe}^{2+}$. In $\mathrm{Su}-$ zuki coupling, the rate-determining step involved oxidative insertion of Pd into bromoanisole. Here under the reaction 
condition, the $\mathrm{Fe}_{2} \mathrm{O}_{3}$ withdraws electrons from $\mathrm{Pd}$ and the partially positively charged $\mathrm{Pd}$ might be more vulnerable to the oxidative addition by bromoanisole.

As we also demonstrated the size-dependence of SMSI in $\mathrm{Pd}-\mathrm{Fe}_{2} \mathrm{O}_{3}$ NHSs, we conclude that by simultaneously tuning the geometric (structural) parameter of NHSs and the reaction environment around them, the properties of these NHSs could be modulated. The current work presents a direct evidence for the connection of the geometrical and environment-dependent electronic effects in the catalytic study.

\section{CONCLUSION}

In summary, we synthesized size-controlled Pd NPs and $\mathrm{Pd}-\mathrm{Fe}_{2} \mathrm{O}_{3}$ NHSs and tested their performances in Suzuki coupling. Then we studied the electronic structure of $\mathrm{Pd}$ $\mathrm{Fe}_{2} \mathrm{O}_{3}$ NHSs in vacuum, in $\mathrm{K}_{2} \mathrm{CO}_{3}$ solution and with the addition of chemio-adsorptive bromoanisole. It was found that in the three cases, the electronic structures of the NHSs were totally different. We suggest that in the study of SMSI, characterization of the electronic structure in vacuum is not enough and sometimes misleading. We hope that our results would shed light on the study of SMSI in other liquid-solid catalysis.

\section{Received 23 September 2014; accepted 30 October 2014;} published online 27 November 2014

1 Carbone L, Cozzoli PD. Colloidal heterostructured nanocrystals: synthesis and growth mechanisms. Nano Today, 2010, 5: 449-493

2 Costi R, Saunders AE, Banin U. Colloidal hybrid nanostructures: a new type of functional materials. Angew Chem Int Ed, 2010, 49: 4878-4897

3 Li Y. Nanoparticle chemistry upgrades catalytic in-terfaces in noble metal catalysts. Sci China Chem, 2014, 57: 924-925

4 Tauster SJ, Fung SC, Garten RL. Strong metal-support interactions. Group 8 noble metals supported on titanium dioxide. J Am Chem Soc, 1978, 100: 170-175

5 Tauster SJ. Strong metal-support interactions. Acc Chem Res, 1987, 20: 389-394

6 Fu Q, Wagner T. Interaction of nanostructured metal overlayers with oxide surfaces. Surf Sci Rep, 2007, 62: 431-498

7 Yang H. Ji S, Liu X, Zhang D, Shi D. Magnetically recyclable Pd/ gamma-AlOOH@ $\mathrm{Fe}_{3} \mathrm{O}_{4}$ catalysts and their catalytic performance for the Heck coupling reaction. Sci China Chem, 2014, 57: 866-872

8 George SM. Introduction: heterogeneous catalysis. Chem Rev, 1995, 95: 475-476

9 Clark JH, Macquarrie DJ. Heterogeneous catalysis in liquid phase transformations of importance in the industrial preparation of fine chemicals. Org Proc Res Dev, 1997, 1: 149-162

10 Shekhar M, Wang J, Lee WS, et al. Size and support effects for the water-gas shift catalysis over gold nanoparticles supported on model $\mathrm{Al}_{2} \mathrm{O}_{3}$ and $\mathrm{TiO}_{2}$. J Am Chem Soc, 2012, 134: 4700-4708

11 Metin O, Ho SF, Alp C, et al. Ni/Pd core/shell nanoparticles supported on graphene as a highly active and reusable catalyst for Suzuki-Miyaura cross-coupling reaction. Nano Res, 2013, 6: 10-18

12 Li C, Fan F, Yin B, et al. $\mathrm{Au}^{+}$-cetyltrimethylammonium bromide solution: a novel pre-cursor for seed-mediated growth of gold nanoparticles in aqueous solution. Nano Res, 2013, 6: 29-37

13 Cargnello M, Doan-Nguyen VVT, Gorgon TR, et al. Control of metal nanocrystal size reveals metal-support interface role for ceria catalysts. Science, 2013, 341: 771-773

14 Dasgupta NP, Liu C, Andrews S, Prinz FB, Yang P. Atomic layer deposition of platinum catalysts on nanowire surfaces for photoelectrochemical water reduction. J Am Chem Soc, 2013, 135: 12932-12935

15 Schweinberger FF, Berr MJ, Döblinger M, et al. Cluster size effects in the photocatalytic hydrogen evolution reaction. J Am Chem Soc, 2013, 135: 13262-13265

16 Toebes ML, van Dillen JA, de Jong KP. Synthesis of supported palladium catalysts. J Mol Cata A Chem, 2001, 173: 75-98

17 Alayoglu S, Krier JM, Michalak WD, et al. In situ surface and reaction probe studies with model nanoparticle catalysts. ACS Cata, 2012, 2: 2250-2258

18 Nowotny J, Bak T, Sheppard LR, Nowotny MK. Reactivity of titanium dioxide with oxygen at room temperature and the related charge transfer. J Am Chem Soc, 2008, 130: 9984-9993

19 Atkinson RJ, Posner AM, Quirk JP. Adsorption of potential-determining ions at the ferric oxide-aqueous electrolyte interface. J Phys Chem, 1967, 71: 550-558

20 Zhang S, Nguyen L, Zhu Y, et al. In-situ studies of nanocatalysis. Acc Chem Res, 2013, 46: 1731-1739

21 Frenkel AI, Rodriguez JA, Chen JG. Synchrotron techniques for in situ catalytic studies: capabilities, challenges, and opportunities. ACS Cata, 2012, 2: 2269-2280

22 Xu B, Zhang Z, Wang X. Formamide: an efficient solvent to synthesize water-soluble and sub-ten-nanometer nanocrystals. Nanoscale, 2013, 5: 4495-4505

23 Jia CJ, Sun LD, Yan ZG, et al. Single-crystalline iron oxide nanotubes. Angew Chem Int Ed, 2005, 44: 4328-4333

24 Peng HC, Xie S, Park J, Xia X, Xia Y. Quantitative analysis of the coverage density of $\mathrm{Br}$-ions on $\mathrm{Pd}\{100\}$ facets and its role in controlling the shape of Pd nanocrystals. J Am Chem Soc, 2013, 135: 3780-3783

25 Miyaura N, Suzuki A. Palladium-catalyzed cross-coupling reactions of organoboron compounds. Chem Rev, 1995, 95: 2457-2483

26 Littke AF, Fu GC. Palladium-catalyzed coupling reactions of aryl chlorides. Angew Chem Int Ed, 2002, 41: 4176-4211

27 Reetz MT, Breinbauer R, Wanninger K. Suzuki and Heck reactions catalyzed by preformed palladium clusters and palladium/nickel bimetallic clusters. Tetra Lett, 1996, 37: 4499-4502

28 Maegawa T, Kitamura Y, Sako S, et al. Heterogeneous Pd/C-catalyzed ligand-free, room-temperature Suzuki-Miyaura coupling reactions in aqueous media. Chem A Eur J, 2007, 13: 5937-5943

29 Ellis PJ, Fairlamb IJS, Hackett SFJ, Wilson K, Lee AF. Evidence for the surface-catalyzed Suzuki-Miyaura reaction over palladium nanoparticles: an operando XAS study. Angew Chem Int Ed, 2010, 122: $1864-1868$

30 Zhang Z, Yates JT. Band bending in semiconductors: chemical and physical consequences at surfaces and interfaces. Chem Rev, 2012, 112: 5520-5551

31 Bruix A, Migani A, Vayssilov GN, et al. Effects of deposited Pt particles on the reducibility of $\mathrm{CeO}_{2}(111)$. Phys Chem Chem Phys, 2011, 13: 11384-11392

32 Min BK, Friend CM. Heterogeneous gold-based catalysis for green chemistry: low-temperature CO oxidation and propene oxidation. Chem Rev, 2007, 107: 2709-2724

33 Morrison SR (ed.). Electrochemistry at Semiconductor and Oxidized Metal Electrodes. New York: Plenum Press, 1980

34 Ye M, Gong J, Lai Y, Lin C, Lin Z. High-efficiency photoelectrocatalytic hydrogen generation enabled by palladium quantum dots-sensitized $\mathrm{TiO}_{2}$ nanotube arrays. J Am Chem Soc, 2012, 134: 15720-15723 
35 Mazeina L, Navrotsky A. Enthalpy of water adsorption and surface enthalpy of goethite $(\alpha-\mathrm{FeOOH})$ and hematite $\left(\alpha-\mathrm{Fe}_{2} \mathrm{O}_{3}\right)$. Chem Mater, 2007, 19: 825-833

36 Li J, Zhu S, Li Y, Wang, F. Water adsorption on Pd $\{100\}$ from first principles. Phys Rev B, 2007, 76: 235433

37 Hesleitner P, Kallay N, Matijevic E. Adsorption at solid/liquid interfaces. 6 . The effect of methanol and ethanol on the ionic equilibria at the hematite/water interface. Langmuir, 1991, 7: 178-184

38 Wang ED, Xu JB, Zhao TS. Density functional theory studies of the structure sensitivity of ethanol oxidation on palladium surfaces. J Phys Chem C, 2010, 114: 10489-10497

39 Bargar JR, Kubicki JD, Reitmeyer R, Davis JA. ATR-FTIR spectroscopic characterization of coexisting carbonate surface complexes on hematite. Geo Cosmo Acta, 2005, 69: 1527-1542

40 Lin Y, Yuan G, Sheehan S, Zhou S, Wang D. Hematite-based solar water splitting: challenges and opportunities. Energy Environ Sci, 2011, 4: 4862-4869

41 de Vries JG. A unifying mechanism for all high-temperature Heck reactions. The role of palladium colloids and anionic species. Dalton Trans, 2006, 421-429

42 Pérez-Lorenzo M. Palladium nanoparticles as efficient catalysts for Suzuki cross-coupling reactions. J Phys Chem Lett, 2011, 3: 167174

43 Molnár Á. Efficient, selective, and recyclable palladium catalysts in carbon-carbon coupling reactions. Chem Rev, 2011, 111: 22512320
44 Yang J, Ying JY. Nanocomposites of $\mathrm{Ag}_{2} \mathrm{~S}$ and noble metals. Angew Chem Int Ed, 2011, 50: 4637-4643

45 Ho VTT, Pan CJ, Rick J, Su WN, Hwang BJ. Nanostructured $\mathrm{Ti}_{0.7} \mathrm{Mo}_{0.3} \mathrm{O}_{2}$ support enhances electron transfer to Pt: high-performance catalyst for oxygen reduction reaction. J Am Chem Soc, 2011, 133: 11716-11724

46 Gross E, Somorjai G. The impact of electronic charge on catalytic reactivity and selectivity of metal-oxide supported metallic nanoparticles. Top Catal, 2013, 56: 1049-1058

Acknowledgements This work was supported by the National Natural Science Foundation of China (NSFC) (91127040, 21221062), and the State Key Project of Fundamental Research for Nanoscience and Nanotechnology (2011CB932402).

Author contributions $\mathrm{Xu} \mathrm{B}$ designed and performed the syntheses and characterizations; Yang $\mathrm{H}$ conceived and conducted the theoretical calculations. Zhou G and Wang X supervised the theoretical and experimental work, respectively. All authors contributed to the general discussion and wrote the manuscript together.

Conflict of interest The authors declare that they have no conflict of interest.

Supplementary information Supplementary data and more discussion are available in the online version of the paper.

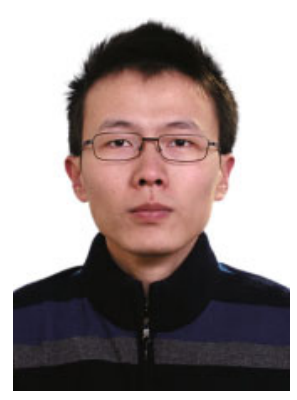

Biao Xu was born in 1987. He received the PhD degree in Chemistry from Department of Chemsitry, Tsinghua University, Beijing, China, in 2014. His research interests include synthesis, assembly, characterization and application of nano heterostructure.

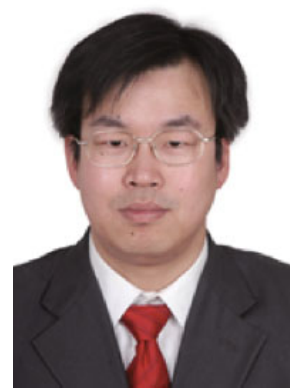

Xun Wang was born in 1976. He received the $\mathrm{PhD}$ degree in Chemistry from Department of Chemistry, Tsinghua University, Beijing, China, in 2004. Currently, he is a professor at the Department of Chemistry, Tsinghua University. His research interests include synthesis, assembly, characterization and application of ultrathin nanomaterials. His main awards include the Finalist for the IUMRS-MRS Singapore Young Researchers Award (2014), Science and Technology Award for Chinese Youth (2009), National Fund for Outstanding Young Scientists (2007) and IUPAC Prize for Young Chemists (2005).

中文摘要 金属-氧化物型纳米异质结构可能存在界面间的电子和物质传输, 因而导致性能的提升, 目前得到广泛的关注. 对于这类金属氧化物型纳米异质结构在催化反应中的结构-效能关系, 以往的研究存在以下不足之处: 一方面对于尺寸的控制还有欠缺, 不能合成尺寸可 控的单分散样品; 另一方面, 对催化剂电子结构的表征主要停留在真空或气相环境, 而液相原位表征方法函待发展. 本研究工作发展了一种 甲酰胺溶剂合成体系, 可以尺寸连续可调地合成一系列钯-氧化铁纳米异质结构和单独的钯纳米晶. 利用这些模型催化剂, 结合液相电化学 测试方法, 我们原位研究了它们的电子结构, 并发现在真空和液相环境中, 这些催化剂的电子结构有明显差异. 这表明传统的真空表征方法 可能会造成与真实构效关系的偏离. 本研究表明, 高质量的模型催化剂和原位表征方法对于研究构效关系都是至关重要的. 这对于发展高 效的金属-氧化物型液-固异相催化剂具有一定的启示意义. 